\title{
Changes of movement patterns from early dispersal to settlement
}

\author{
María del Mar Delgado \& Vincenzo Penteriani \&
}

Vilis O. Nams \& Letizia Campioni

\begin{abstract}
Moving and spatial learning are two intertwined processes: (a) changes in movement behavior determine the learning of the spatial environment, and (b) information plays a crucial role in several animal decision-making processes like movement decisions. A useful way to explore the interactions between movement decisions and learning of the spatial environment is by comparing individual behaviors during the different phases of natal dispersal (when individuals move across more or less unknown habitats) with movements and choices of breeders (who repeatedly move within fixed home ranges), that is, by comparing behaviors between individuals who are still acquiring information vs. individuals with a more complete knowledge of their surroundings. When analyzing movement patterns of eagle owls, Bubo bubo, belonging to three
\end{abstract}

M. M. Delgado

Laboratory of Ecological and Evolutionary Dynamics, Department of Biological and Environmental Sciences, University of Helsinki,

00014 Helsinki, Finland

M. M. Delgado ( $\star)^{\prime}{ }^{\prime}$ V. Penteriani ${ }^{\prime}$ L. Campioni

Department of Conservation Biology,

Estación Biológica de Doñana, C.S.I.C.,

c/Américo Vespucio s/n,

Seville 41092, Spain

e-mail: mmdelgado@ebd.csic.es

V. Penteriani

Finnish Museum of Natural History, Zoological Museum,

Vertebrate Division, University of Helsinki,

00014 Helsinki, Finland

V. O. Nams

Department of Environmental Sciences,

Nova Scotia Agricultural College,

Box 550, Truro NS B2N 5E3, Canada status classes (floaters wandering across unknown environments, floaters already settled in temporary settlement areas, and territory owners with a well-established home range), we found that: (1) wandering individuals move faster than when established in a more stable or fixed settlement area, traveling larger and straighter paths with longer move steps; and (2) when floaters settle in a permanent area, then they show movement behavior similar to territory owners. Thus, movement patterns show a transition from exploratory strategies, when animals have incomplete environmental information, to a more familiar way to exploit their activity areas as they get to know the environment better.

Keywords Bubo bubo · Familiarity · Floater - Learning . Movement behavior . Natal dispersal

Introduction

Animal movement is an essential mechanism underlying many ecological processes at individual (e.g., home ranging, site fidelity, foraging), population (e.g., metapopulation connections and persistence, invasion spreading), community (e.g., assemblages, species coexistence), and ecosystem levels (Nathan 2008; Revilla and Wiegand 2008; Fryxell et al. 2008). The implications of movement behavior on several evolutionary and ecological processes have been recently emphasized (Dingemanse et al. 2003; Davis and Stamps 2004; Hansson et al. 2004; Haughland and Larsen 2004; Nathan 2008; Schick et al. 2008). In particular, spatial memory and learning allow animals to move through their landscape as efficiently as possible (Saarenmaa et al. 1988; Vuilleumier and Perrin 2006). However, there is still a lack of knowledge on the 
characteristics of the process by which individuals learn and acquire experience to move within and through environments (e.g., Dukas 2004).

Cognitive abilities and learning affect behavior and choices related to habitat selection, mate choice, foraging, social interactions, and space use (Dukas 2004; Dall et al. 2005). Until now, most of the models that have been used to explore some aspects of spatial learning have assumed that individuals are "omniscient", i.e., that they have complete information on the quality of all patches in the habitat. However, it is unlikely that individuals could always have an a priori information on the surroundings (e.g., Vos et al. 1998 and references therein; Stamps and Krishnan 1999): individuals need time to acquire knowledge about the surroundings in which they move and, consequently, adopt some site-specific mechanisms or rules which allow them to exploit habitat patches optimally (Stamps 1995; Thield and Hoffmeister 2004; Dall et al. 2005).

Moving and learning are intertwined processes: (a) changes in movement behavior during the different phases of the biological cycle or a switch in an individual status (floater vs. breeder) allow the individuals to better learn about and/or differently perceive their environment, and (b) information plays a crucial role in several animal decisionmaking processes, like movement decisions during natal dispersal, a crucial phase of animal life. Individuals actively sampling novel and temporary patches should show different movement behaviors from when they settle in a stable area. Indeed, natal dispersal presents a unique opportunity to explore interactions among animal movements and learning because of the specific stages that individuals go through (Stamps 2001; Andreassen et al. 2002; Clobert et al. 2004; Bowler and Benton 2005; Heinz and Strand 2006; Baguette and Van Dyck 2007; Delgado and Penteriani 2008), shifting from a wandering to a more stable phase characterized by a settlement in quite fixed areas of activity. Moreover, natal dispersal involves considerable time spent alone traveling across unknown areas, and therefore, the costs of dispersal can be significant because of both mortality risks and missed reproductive opportunities (e.g., Waser et al. 1994; Alberts and Altmann 1995). But the costs of uncertainty during dispersal may be reduced by becoming familiar with the environment. Thus, the comparison of movement behaviors of floaters throughout the dispersal process vs. movements of territory owners within their well-established home ranges presents a unique opportunity to evaluate the effects of local familiarity on animal movement decisions.

The eagle owl Bubo bubo has a multiphase dispersal process (Delgado and Penteriani 2008). At the beginning, during the wandering phase (i.e., the exploratory stage of natal dispersal), individuals survey different unknown areas for a variable time period. Once they find a suitable temporary settlement area, they enter the stop phase of dispersal (Delgado and Penteriani 2008). Such settlement areas represent those zones occupied during the longest time period of the whole dispersal, sometimes until floaters become territory owners and start breeding. At this stage, due to the amount of time they spend in the settlement area, individuals become more familiar with their environment and learn what significant habitat features are in the area, where these are, and how to move to exploit them (Stamps and Krishnan 1999).

By using data from a 4-year radiotracking study on the movement behavior of eagle owls, we tested the following main hypothesis: throughout natal dispersal, the shift from a more wandering and explorative stage to a quite stable settlement stage will increase local familiarity due to increasing spatial learning. As a consequence, we may expect a progressive change in movement patterns: since they become more familiar with their surroundings, owls in their settlement phase (i.e., when they reach the stop phase) should show movement patterns more similar to territory owners than to wandering floaters at the beginning of dispersal. We expect the following: (a) Since animals with a preferred (i.e., learned) diurnal roost site are expected to frequently return to it after their activity period, floating owls in settlement areas and territory owners will show shorter distances between the first and the last location recorded in the same night; (b) Since wandering individuals are continuously exploring novel areas and sampling different patches, they will not show movements within well-defined foraging areas. However, if owls have learned the spatial distribution of resources within their home range once they have settled in an area, they may tend to concentrate their foraging efforts in specific restricted areas; (c) Because individuals dispersing through new habitats vs. individuals moving within their own home range use different spatial domains, the structure of individual movement paths will change. (d) Finally, because dispersal costs are high and floaters only hope is to locate a patch as quickly as possible, wandering owls traveling through unknown environments will travel faster and straighter than individuals moving in a familiar habitat.

\section{Materials and methods}

\section{Data collection}

We radiotagged 40 juveniles (born in 12 breeding sites) and nine territory owners in the 2003-2006 period in the Sierra Morena massif (south-western Spain; for more information see Penteriani et al. 2007). Marked individuals were equipped with a Teflon ribbon backpack harness that carried a 30-g radio-transmitter (Biotrack Ltd, Wareham BH20 5AJ, Dorset, UK; www.biotrack.co.uk). Each trans- 
mitter package and harness weighed less than 3\% of the total body mass (as recommended by the US Geological Survey Bird Banding Laboratory), with a mercury posture sensor that allowed us to discriminate rhythms of activity by changes in the radio signal. Juveniles were radiotagged when they were approximately 35 days old. Because they were still growing, backpacks were adjusted so that the Teflon ribbon could expand. After 4 years of continuous radiotracking, we never recorded a possible adverse effect that could be directly attributed to backpacks on birds (Delgado and Penteriani, unpublished data). Owlets were aged following Penteriani et al. (2005) and sexed $\left(\mathrm{n}_{\text {males }}=\right.$ 26; $\mathrm{n}_{\text {females }}=14$ ) by molecular procedures using DNA extracted from blood (Griffiths et al. 1998).

We followed both territory owners and juveniles ( $n_{\text {wandering }}$ phase $=32$ individuals -19 males and 13 females; $n_{\text {stop }}$ phase $=25$ individuals -18 males and seven females) individually in continuous radiotracking sessions $(n=285$ entire nights-119 for adults and 166 for dispersing during a total time of 1,214 and $1,840 \mathrm{~h}$, respectively). A continuous radiotracking session means following a focal individual during the whole night (i.e., from $1 \mathrm{~h}$ before sunset to $1 \mathrm{~h}$ after sunrise; mean duration of a radiotracking session \pm $\mathrm{SD}=10.56 \pm 0.08 \mathrm{~h})$ and recording a new location $(\mathrm{n}=4,758$ recorded locations; mean total number of locations per individual $\pm \mathrm{SD}=97 \pm 92$ ) each time that we detected a change in individual position (mean number of locations per radiotracking session $\pm \mathrm{SD}=18 \pm 4$ ). Thus, the number of locations recorded is a measure of the amount of movement during the night. The mean time between owl movements was $32.7 \pm 30.8$ min, not being significantly different between categories $\left(F_{2,4,185}=1.7, p=0.1\right)$. We note that: (a) the high variation in the mean number of locations per individual is mainly due to the different activity patterns of each individual; and (b) the low mean number of locations per radiotracking session is due to the large amount of time that the species spend roosting (Penteriani et al. 2008). Individual movements were detected by a fixed antenna located on the roof of a car. Locations were done using triangulation with three-element hand-held Yagi antenna connected to ICOM (IC-R20) portable receivers. To avoid unnecessary disturbance during continuous tracking, we attempted to maintain a distance of at least 100-300 m from the focal animal. In general, the tracking did not seem to affect owl behavior, which appeared to ignore the observer (Delgado and Penteriani, unpublished).

Data analysis

\section{Defining dispersal phases}

To determine the different phases (i.e., start, wandering, and stop phases) of dispersal, we recorded the position of each juvenile weekly, typically when owls were at their diurnal roost sites. For each individual, we plotted both the beeline distance between its natal nest for each weekly location and the individual average of beeline distances between the whole set of locations and the nest (the latter representing the individual global mean distance) covered for each individual during the dispersal period. When juveniles left the nest, they still remained in their parental home range for a while. We considered dispersal to have started when individuals left their parent's home range, which we estimated when the distance of each weekly location from the nest becomes larger than the global mean distance traveled by each animal during the dispersal period (Delgado and Penteriani 2008). After leaving the natal territories, dispersal distances progressively increased. Finally, when owls reached the stop phase of dispersal, dispersal distances leveled off. We considered that owls settled in a stable settlement area when the distances between successive weekly locations became smaller than the average distance of previous moves traveled by each dispersing owl (for more details, see Delgado and Penteriani 2008). The wandering phase encompasses the movements between the start of dispersal and the final settlement in a stable area.

Once dispersing owls settled in a stable settlement area, we never observed a shift again to the wandering phase. However, we could not have detected such behavior if some individuals shifted to the wandering phase after their third year because the battery life was $\sim 2.5$ years. Although such a behavioral shift has been recorded in some other species (e.g., Ferrer 1993a, b), some dead individuals were found more than 4 years after the battery failed (Delgado and Penteriani, unpublished results) in the same settlement area where they were located the last time. To better understand individual behavior across the whole natal dispersal, we are now marking "older" dispersing owls directly in their settlement areas (Penteriani and Delgado, unpublished results).

\section{Owl status, movements, and spatial learning}

To find out how movements at each floater stage differed from the breeding stage, we compared three different aspects: roost sites, foraging areas, and spatial domains.

Roost sites To analyze if animals frequently return to a given roost site, we calculated the distance between the first and the last owl location recorded on the same night, i.e., before the start and after the end of the nightly activities).

Foraging areas Firstly, we calculated the activity areas for both dispersing and breeding individuals. For each individual night, activity area was estimated using the $95 \%$ kernel 
of all night locations (fixed-kernel method, Worton 1989), and core area estimated using the 50\% kernel. We used the fixed kernel least squares cross-validation estimate because it is best at defining interior contours (Seaman et al. 1999; Blundell et al. 2001). Secondly, we used this information to: (a) identify foraging areas: by recording hunting events (see Penteriani et al. (2008) for more details), we were able to discriminate foraging areas from other areas of intensive use (e.g., refuges); and (b) calculate their extensions relating to the $95 \%$ area of floaters' vital ranges and breeders' home ranges.

Spatial domains Animals often react differently to their environment at different spatial scales (these areas of spatial scales are called spatial domains); we used fractal analysis to determine these spatial domains (as in Nams and Bourgeois 2004). To test for changes in movement paths (following Nams 2005), we measured: (1) path tortuosity (D) of each nightly movement path as a function of spatial scale. Fractal $D$ measures movement path tortuosity, where $D=1$ indicates a perfectly straight line, and $D=2$ suggests approximately Brownian (plane-filling) movement. To look for variation in $D$ with changes in the spatial scales, we determined the value of $D$ for a series of small ranges of divider size ranging from 20 to 1,000 using Vfractal estimator (Fractal 4.0 software; see Nams 2005 for a detailed explanation of the procedure). Window sizes at each spatial scale were chosen with a minimum value of midpoint/1.35 and a maximum value of midpoint $\times 1.35$. This window size definition gave symmetrical, fixed width windows on the log-transformed spatial-scale axis (Nams 2005). A discontinuity in fractal $D$ vs. scale relationship indicates a change in path structure from one spatial domain to another; (2) the movement path heterogeneity by dividing the path into segments and estimating the variance in tortuosities among segments. The resulting plots of divider size vs. $\mathrm{D}$ were used to describe the pattern of scale variance. The specific pattern of scale variance may provide information on the spatial scales at which the animal views the landscape (Nams 2005). A sharp drop in the variance of tortuosity also indicates a change in path structure from one domain to another; and (3) the correlation in tortuosity between pairs of adjacent segments of the total path, as a function of segment length. If the segments are much smaller than patch sizes, then their correlation would be positive because both path segments would be either inside or outside of a patch. For segments that are the size of patches, one would be in a patch (and therefore tortuous), while the adjacent would be outside (and therefore straight), and thus, their correlation would be negative. Finally, when segments are large enough to cover several patches, then their correlation would be zero. Thus, when there is a zero correlation at all scales, this means no patch use, while a positive correlation of tortuosities dropping to a negative correlation indicated a patch use. In such a case, patch size may be estimated as the spatial scale at which the correlation declines below zero (Nams 2005).

Finally, in order to characterize owls' motor skills (i.e., how individuals exploit the elements inside the space in which they move), we estimated various movement path statistics. First, we estimated path tortuosity, by the overall fractal dimension (D). This was done using the same range of spatial scales for all individuals (from 20 to $160 \mathrm{~m}$ ), with the upper limit set at less than half the lengths of the longest path, and the lower limit the minimum distance between locations (Halley et al. 2004). Using the same range of scales allowed us to compare fractal D among paths even though D varied with scale (Turchin 1996; Nams and Bourgeois 2004). D was computed using the fractal mean estimator with the program Fractal (Nams 1996, 2006a), and fractal $D$ was normalized by $\log (D-1)$. Finally, we estimated the overall traveling speed, mean step lengths, and the total length of nightly movement paths. Both the overall speed and the total path length were based on the gross distance traveled.

\section{Statistical analyses}

Because repeated measures were made for each owlet, we considered individuals as sampling units (SUBJECT Statement in PROX MIXED) and used a repeated measurements mixed model (PROX MIXED in SAS software; SAS Institute 2001), including sex as a random factor. Moreover, since we radiotagged many owls per nest, we also tested the possible effect of nest as an additional random effect (Littell et al. 1996). But the effect of sex and nest was never significant (always $p>0.10$ ), and they were therefore removed from the models. We used a restricted maximum likelihood method to estimate all the unknown variancecovariance parameters (Jennrich and Schluchter 1986) and selected autoregressive (AR1) as the covariance structure that best fitted the Akaike Information Criterion (AIC). The variance structure with the lowest AIC value is deemed the best one. Finally, statistical significance was considered to be $\alpha<0.05$.

\section{Results}

Most juveniles started their dispersal at the end of August (mean age at the beginning of dispersal $( \pm \mathrm{SD})=170 \pm$ 20.51 days old, range $=131-232$ days old). Although there was a high degree of individual variation, $30 \%$ of eagle owls found a stable settlement area (i.e., shifted from the wandering to the stop phase of dispersal) in the middle of 
March (mean dispersal age of the stop phase $( \pm S D)=395 \pm$ 109.86 days old, range $=181-640$ days old). The time between when a disperser finds a settlement area and becomes a breeder is very unpredictable in this species. We observed some dispersing owls that accidentally crossed an empty territory or that arrived close to an available mate halfway during the wandering route, settled and became breeders, when they were only 1 year old. On the other hand, and more commonly, other dispersers that encountered a stable settlement area and decided to settle remained there for several years without breeding.

Floaters during the wandering phase traveled significantly further (net distances) during the night than both floaters during the stop phase and territory owners $\left(\mathrm{F}_{2,3}=\right.$ 14.99, $\mathrm{p}<0.0001$; Table 1). As expected, individuals already established in a stable area (floaters in their settlement areas or territory owners) come back to a given roost site or area more frequently than did owls during the wandering phase, i.e., they traveled shorter (net distances) during the night. On the contrary to what was hypothesized for foraging areas, we did not detect any significant differences in the relative size of the foraging areas $\left(F_{2,3}=\right.$ 2.06, $p=0.13$ ) among the different life stages. However, the relative size of foraging areas gradually decreased (Table 1) from territory owners to the wandering phase of dispersal. The floaters in the stop phase showed an intermediate behavior between wandering and territorial owls.

There was a gradual change in response to spatial scale across the two phases of dispersal (Fig. 1). During the wandering phase of dispersal, owls moved with homogeneous movement paths, as shown by the continuous change in fractal $D$ and the variance of fractal $D$ with spatial scale and the non-positive values of correlation (Fig. 1). On the other hand, territory owners showed the most heterogeneous paths, with strong responses at different spatial scales (Fig. 1). This was shown by the drop in fractal $D$ and variance at $\sim 350 \mathrm{~m}$ and the crossing of the $\mathrm{y}$-axis from positive to negative values by the correlation at $\sim 300 \mathrm{~m}$. These indicate two potential domains of scale for territory owners, suggesting that their movement paths differed qualitatively at scales of below $300 \mathrm{~m}$ and above $350 \mathrm{~m}$.
At scales below $300 \mathrm{~m}$, the shape of the fractal D curve is similar to that of a correlated random walk, but at scales above $350 \mathrm{~m}$, the shape is more similar to a directed walk (Nams 2006b); thus, perhaps, the owls traveled with more directed movement at larger scales. The owls in the stop phase showed intermediate responses to the wandering and territorial owls.

Almost all variables describing motor skills experienced a gradual but significant transition from the beginning of dispersal to the acquisition of a territory. Wandering individuals with an incomplete information of the environment traveled faster $\left(F_{2,3}=5.73, p=0.0048\right.$; Table 1$)$ with longer step lengths $\left(F_{2,3}=7.90, p=0.0005\right.$; Table 1$)$ and had the longest $\left(F_{2,3}=12.09, p=0.0001\right.$; Table 1$)$ and straightest trajectories $\left(F_{2,3}=6.51, p<0.0021\right.$; Table 1$)$. On the contrary, territory owners moved slower, with shorter and more tortuous movement paths. Floaters in the stop phase clearly represented a transition stage between wandering owls and territory owners, characterized by high traveling speed but quite shorter and more tortuous movement trajectories than floaters during the transition phase (Table 1).

\section{Discussion}

Animals living in a changing world have to continuously reduce uncertainty by gathering information (Dall and Johnstone 2002). Our findings suggest that movement behavior experienced a transition from wandering exploratory strategies to a more specific use of spatial resources, when it is supposed that individuals increase the value of familiar space.

At the beginning of dispersal, when individuals frequently travel across unfamiliar (and sometimes unfavorable) areas, they have less time to become familiar with their surroundings. Uncertainty regarding location of conspecifics, predators, and resources may pose significant problems (Stamps 1995; Stamps and Krishnan 1999; Dall et al. 2005). But the costs of uncertainty during dispersal may be reduced by becoming familiar with the spatial and
Table 1 Estimates of focal movement parameters for both types of floaters $\left(\mathrm{n}_{\text {wandering phase }}=\right.$ 32; $n_{\text {stop phase }}=25$ ) and territory owners $(n=9)$

Roost site distance between the first and last owl locations of the night, foraging area proportion of the total home range

\begin{tabular}{lccr}
\hline & $\begin{array}{l}\text { Juveniles (wandering phase; } \\
\text { mean } \pm \text { SE) }\end{array}$ & $\begin{array}{l}\text { Juveniles (stop phase; } \\
\text { mean } \pm \text { SE) }\end{array}$ & $\begin{array}{l}\text { Territory owners } \\
\text { (mean } \pm \text { SE) }\end{array}$ \\
\hline Roost site (m) & $1,396.54 \pm 174.67$ & $725.25 \pm 67.21$ & $762.86 \pm 77.12$ \\
Foraging areas (\%) & $0.12 \pm 0.009$ & $0.10 \pm 0.007$ & $0.09 \pm 0.007$ \\
Speed (m/h) & $874.98 \pm 54.26$ & $801.06 \pm 35.82$ & $641.75 \pm 37.07$ \\
Fractal D & $1.06 \pm 0.005$ & $1.08 \pm 0.005$ & $1.09 \pm 0.006$ \\
Path length (m) & $9,958.56 \pm 614.63$ & $9,248.99 \pm 395.25$ & $6,676.09 \pm 359.73$ \\
Step length (m) & $608.16 \pm 21.78$ & $546.70 \pm 32.94$ & $456.68 \pm 23.42$ \\
\hline
\end{tabular}




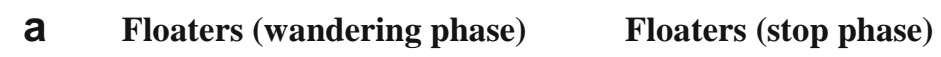

Territory owners
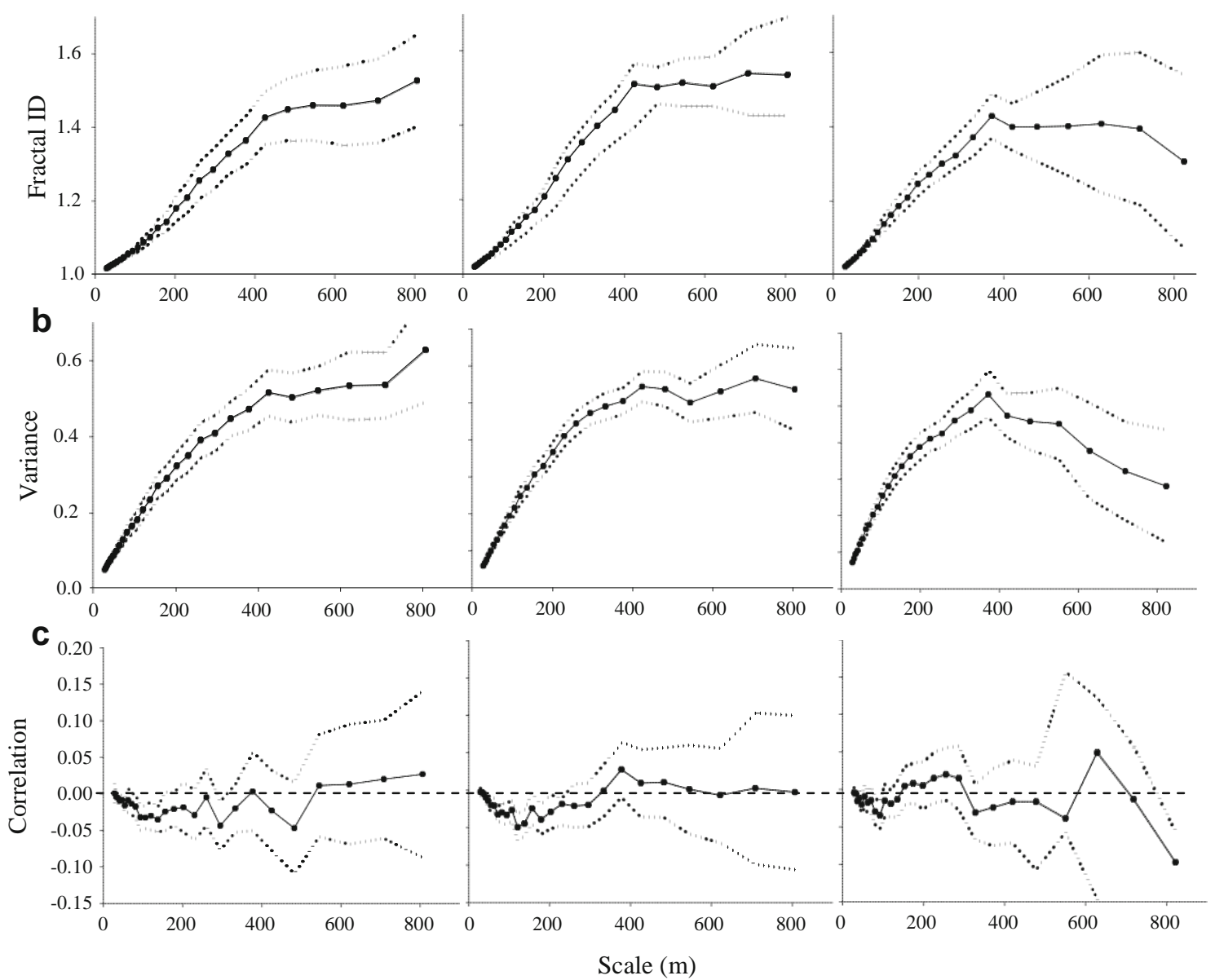

Fig. 1 Movement patterns of floating owls (during the wandering and the stop phases of natal dispersal) and territory owners, as represented by three statistics estimated at different spatial scales (more detailed information in the text): a fractal $D$, as a measure of path tortuosity; $b$ variance, an index of variance in tortuosity among path segments; and c correlation, which measures correlation in fractal D between

adjacent path segments. Dispersing owls showed homogeneous movement paths (i.e., defining a unique domain of scale), while territory owners showed two domains of scale (i.e., they were traveling with heterogeneous paths): below $300 \mathrm{~m}$ and above $350 \mathrm{~m}$. Dotted lines represent 95\% confidence intervals

social environment, e.g., searching actively for temporary, stable settlement areas. This phenomenon is evidenced by the observed changes in movement patterns shown by dispersing owls when they reach a settlement area. At that moment, although floaters never show territorial displays (Delgado and Penteriani, unpublished results), they do have a well-defined home range, as has been reported for the floaters of some bird species (e.g., Smith 1978; Arcese 1989; Zack and Stutchbury 1992). However, our results highlight that the home range of floating birds is not a characteristic of the floating population from their beginning (i.e., when individuals start natal dispersal), but a consequence of the time they have spent as dispersing individuals.

The benefits of local familiarity have been generally linked with the increase in foraging efficiency, breeding performance, and survival (Pärt 1995). By learning the

physical and social structures of their environment, floaters can remember the location and qualities of the resources they learn about (e.g., roost sites and foraging areas), attend to conflicting needs and sensory inputs, engage in social interaction, and balance all of these considerations. Even though we did not detect any significant differences in the relative size of the foraging areas among the different life stages, preferred foraging areas within the home ranges used by floaters during both the wandering and the stop phases of dispersal seemed to be less restricted than for territory owners. This could be interpreted as the result of individual adjustment responses of foraging behavior to local habitat structure (Fortin 2002). Since the vital ranges of floating owls are not defended (the floater social status does not include territorial disputes), a non-breeder has a higher mobility within its range, allowing it to displace among different hunting areas more easily than a breeder. 
Constrictions such as complex social organization and territoriality among neighbors could oblige territory owners to respect the limit of their hunting areas to avoid the high cost of intrusions in neighboring territories and consequent territorial contests.

We consider it important to underline here that the concepts of territory and home range involve pivotal differences that explain some of our results. Home ranges refer to areas: (a) over which an animal travels in its day-today activities to join the most focal elements for their survival; (b) which, due to the scattered distribution of resources, also include large portions of landscape that individuals are just passing through; and, consequently, (c) that are too large to be efficiently protected from intrusions (e.g., eagle owls are territorial only in a restricted portion of the home range; Delgado and Penteriani 2007). On the other hand, territories refer to an exclusive portion of the whole home range that is defended to exclude other conspecifics (Maher and Lott 1995) and, consequently, does not overlap with the home range of neighboring residents. These differences between home ranges and territories explain some of the different behaviors we observed. To improve the efficacy of territory acquisition and defense, territory owners exhibit a complex array of behavioral patterns, such as site-specific aggressiveness, the ability to discriminate neighbors from intruders, and contests involving complicated exchanges of communication signals (for more information, see also Penteriani et al. 2007). Floaters, who do not show such behavioral displays because they do not actively defend an exclusive area, can benefit from living in a restricted area through gaining knowledge of the habitat and establishing dominance relations with other floaters and territory owners (Smith 1978; Stutchbury 1991; Bruinzeel and van de Pol 2004).

The needs for territorial tasks (as well as reproductive ones) of territory owners could contribute to the slower movements of territory owners in comparison to floaters during dispersal. For example, territory owners spend large amounts of time calling on posts located close to the core areas of their home range, both for territorial demarcation and mate-mate communication (Delgado and Penteriani 2007). This means long pauses of territory owners on strategic posts, which are not included in the time budget of floaters that mainly roost, hunt, and survey new areas (Delgado and Penteriani, unpublished data).

Differences in the speed of movement may also have generated the detected differences in the patterns of patch use between dispersers and territory owners, which in turn may also be reflecting differences in individual perceptive resolutions (With 1994). Animal perceptive resolution, which may integrate sensory perceptive abilities, physical constraints, and behavioral preference, is inversely related with the rate of movement. The ability of animals to perceive habitat heterogeneity at small scales decreases as speed increase, whereas the spatial extent at which they operate increases (Kolasa and Rollo 1991). Because floaters moved faster than territory owners, floaters perceive environmental patterns at a larger spatial scale, and as a consequence, dispersing owls show a large and unique domain of scale. On the other hand, territory owners can operate at different and well-defined domains of scale, each one reflecting different aspects of their biology (e.g., foraging behavior, crossing home range, and reproduction).

Animal movement behavior can be classified into random and systematic strategies (Fortin 2002). In systematic movement strategies (such as the ones shown by owners and well-settled floaters), which only work when some a priori relevant information is available, the rules to optimally cover a given area are based on quite fixed and controlled plans. By contrast, in a random strategy (such as the one shown by wandering floaters), animals must attempt to move in order to optimize their chances of locating resources (i.e., food, mates, shelter, breeding habitats), the search rules rely on stochastic processes. Although it is not possible to completely neglect the existence of chance in nature, sensorial or cognitive improvements could override the need of random search in nature by, e.g., creating more and better sensory cues, improving high-level environmental information processing mechanisms, and synchronizing spatial variations of the abundances of resources.

Dispersal costs are many and might include the risk of starvation and other mortality (see Stamps et al. 2005 and reference therein). In general, animals dispersing through an inhospitable and unknown habitat should follow straighter paths, to better avoid redundant searches and to locate a patch as quickly as possible (Zollner and Lima 1999). Wiens et al. (1995) found that darkling beetles (Eleodes obsoleta) move in straighter paths through highrisk areas than they do through low-risk ones. A variety of other organisms (Crist and MacMahon 1991; Madison 1997) follow straighter paths when displacing long distances through unknown habitats. When habitat features are known, as is the case for floaters during the stop phase and territory owners, individuals should be able to efficiently regulate their movements (Klaassen et al. 2006): owls in the stop phase adjusted the length and the tortuosity of their movements, showing movement patterns more similar to territory owners than wandering floaters.

To conclude, while spatial familiarity is undoubtedly one of the multiple key factors in determining movement patterns, the patterns that we recorded can be also considered to be the result of diverse individual needs associated with different social status. That is, two nonmutually exclusive elements affect movement behavior: learning of the spatial environment that individuals move 
across and social status of the individuals (e.g., wandering floaters vs. breeders).

Acknowledgments For their help in the field work, we are grateful to P. Bartolommei, R. Lourenço, and G. Penteriani. The first draft was improved by the criticisms of R. Avni and E. Revilla. We are grateful to E. Korpimäki and two anonymous referees for their comments on the first draft of the manuscript. The work was funded by a research project of the Spanish Ministry of Science and Innovation (CGL200802871/BOS). During this work, M. M. Delgado was supported by a postdoctoral grant of the Spanish Ministry of Science and Innovation. We manipulated and marked owls under the Junta de AndalucíaConsejería de Medio Ambiente permit nos. SCFFS-AFR/GGG RS260/02 and SCFFS-AFR/CMM RS-1904/02.

\section{References}

Alberts S, Altmann J (1995) Balancing costs and opportunities: dispersal in male baboons. Am Nat 145:279-306

Andreassen HP, Stenseth NC, Ims RA (2002) Dispersal behaviour and population dynamics of vertebrates. In: Bullock JM, Kenward RE, Hails RS (eds) Dispersal ecology, the $42^{\text {nd }}$ Symposium of the British Ecological Society held at the University of Reading, 2-5 April 2001. Blackwell, Oxford, pp 237-256

Arcese P (1989) Territory acquisition and loss in male song sparrows. Anim Behav 37:45-55

Baguette M, Van Dyck H (2007) Landscape connectivity an animal behavior: functional grain as a key determinant for dispersal. Landsc Ecol 22:1117-1129

Blundell GM, Maier JAK, Debevec EM (2001) Linear home ranges: effects of smoothing, sample size, and autocorrelation on kernel estimates. Ecol Monogr 71:469-489

Bowler DE, Benton TG (2005) Causes and consequences of animal dispersal strategies: relating individual behavior to spatial dynamics. Biol Rev 80:205-225

Bruinzeel LW, van de Pol M (2004) Site attachment of floaters predicts success in territory acquisition. Behav Ecol 15:290-296

Clobert J, Ims RA, Rousset F (2004) Causes, mechanisms and consequences of dispersal. In: Hanski I, Gaggiotti OE (eds) Ecology, genetics, and evolution of metapopulations. Academic, London, pp 307-335

Crist TO, MacMahon JA (1991) Individual foraging components of harvester ants: movement patterns and seed patch fidelity. Insectes Soc 38:379-396

Dall SRX, Johnstone RA (2002) Managing uncertainty: information and insurance under the risk of starvation. Philos Trans R Soc B 357:1519-1526

Dall SRX, Giraldeau LA, Olsson O, McNamara JM, Stephens DW (2005) Information and its use by animals in evolutionary ecology. Trends Ecol Evol 20:187-193

Davis JM, Stamps JA (2004) The effect of natal experience on habitat preferences. Trends Ecol Evol 19:411-416

Delgado MM, Penteriani V (2007) Vocal behaviour and neighbour spatial arrangement during vocal displays in Eagle owl (Bubo bubo). J Zool 271:3-10

Delgado MM, Penteriani V (2008) Behavioral states help translate dispersal movements into spatial distribution patterns of floaters. Am Nat 172:475-485

Dingemanse NJ, Both C, van Noordwijk AJ, Rutten AL, Drent PJ (2003) Natal dispersal and personalities in great tits (Parus major). Proc R Soc Lond B 270:741-747

Dukas R (2004) Evolutionary biology of animal cognition. Annu Rev Ecol Evol Syst 35:347-374
Ferrer M (1993a) Reduction in hunting success and settlement strategies in young Spanish imperial eagles. Anim Behav 45:406-408

Ferrer M (1993b) Juvenile dispersal behaviour and natal philopatry of a long-lived raptor, the Spanish imperial eagle Aquila adalberti. Ibis 135:132-138

Fortin D (2002) Optimal searching behaviour: the value of sampling information. Ecol Model 153:279-290

Fryxell JM, Hazell M, Börger L, Dalziel BD, Haydon DT, Morales JM (2008) Multiple movement modes by large herbivores at multiple spatiotemporal scales. Proc Natl Acad Sci U S A 105:19114-19119

Griffiths R, Double MC, Orr K, Dawson RJG (1998) A DNA test to sex most birds. Mol Ecol 7:1071-1075

Halley JM, Hartley S, Kallimanis AS, Kunin WE, Lennon JJ, Sgardelis SP (2004) Uses and abuses of fractal methodology in ecology. Ecol Lett 7:254-271

Hansson B, Bensch S, Hasselquist D (2004) Lifetime fitness of shortand long distance dispersing great reed warblers. Evolution 58:2546-2557

Haughland DL, Larsen KW (2004) Exploration correlates with settlement: red squirrel dispersal in contrasting habitats. J Anim Ecol 73:1024-1034

Heinz SK, Strand E (2006) Adaptative patch searching strategies in fragmented landscape. Evol Ecol 20:113-130

Jennrich RI, Schluchter MD (1986) Unbalanced repeated-measures models with structured covariance matrices. Biometrics 42:805820

Klaassen RHG, Nolet BA, Bankert D (2006) Movement of foraging Tundra swans explained by spatial pattern in cryptic food densities. Ecology 87:2244-2254

Kolasa J, Rollo CD (1991) Introduction: the heterogeneity of heterogeneity: a glossary. In: Kolasa J, Pickett STA (eds) Ecological heterogeneity. Springer, New York, pp 1-23

Littell RC, Milliken GA, Stroup WW, Wolfinger RD (1996) SAS system for mixed models. SAS Institute, Cary

Madison DM (1997) The emigration of radio-implanted spotted salamanders, Ambystoma maculatum. J Herpetol 31:542-551

Maher CR, Lott DF (1995) Definitions of territoriality used in the study of variation in vertebrate spacing systems. Anim Behav 49:1581-1597

Nams VO (1996) The Vfractal: a new estimator for fractal dimension of animal movement paths. Landsc Ecol 11:289-297

Nams VO (2005) Using animal movement paths to measure response to spatial scale. Oecologia 143:179-188

Nams VO (2006a) Improving accuracy and precision in estimating fractal dimension of animal movement paths. Acta Biotheor 54:1-11

Nams VO (2006b) Detecting oriented movement of animals. Anim Behav 72:1197-1203

Nams VO, Bourgeois M (2004) Using fractal analysis to measure habitat use at different spatial scales: an example with marten. Can J Zool 82:1738-1747

Nathan R (2008) An emerging movement ecology paradigm. Proc Natl Acad Sci U S A 105:19050-19051

Pärt T (1995) The importance of local familiarity and search costs for age- and SE-biased philopatry in collared flycatcher. Anim Behav 49:1029-1038

Penteriani V, Delgado MM, Maggio C, Aradis A, Sergio F (2005) Development of chicks and pre-dispersal behaviour of young in the eagle owl Bubo bubo. Ibis 147:155-168

Penteriani V, Delgado MM, Alonso-Alvarez C, Sergio F (2007) The importance of visual cues for nocturnal species: eagle owls signal by badge brightness. Behav Ecol 18:143-147

Penteriani V, Delgado MM, Bartolommei P, Maggio C, AlonsoAlvarez C, Holloway GJ (2008) Owls and rabbits: predation against substandard individuals of an easy prey. J Avian Biol 39:215-221 
Revilla E, Wiegand T (2008) Individual movement behavior, matrix heterogeneity, and the dynamics of spatially structured populations. Proc Natl Acad Sci U S A 105:19120-19125

Saarenmaa H, Stone ND, Folse LJ, Packard JM, Grant WE, Makela ME, Coulson RN (1988) An artificial intelligence modeling approach to simulating animal/habitat interaction. Ecol Model 44:125-141

SAS Institute (2001) SAS/STAT software: changes and enhancements, version 8.2. SAS, Cary

Schick RS, Scott RL, Colchero F, Best BD, Boustany A, Conde DA, Halpin PN, Joppa LN, McClellan CM, Clark JS (2008) Understanding movement data and movement processes: current and emerging directions. Ecol Lett 11:1338-1350

Seaman DE, Millspaugh JJ, Kernohan BJ, Brundige GC, Raedeke KJ, Gitzen RA (1999) Effects of sample size on kernel home range estimates. J Wildl Manage 63:739-747

Smith SM (1978) The "underworld" in a territorial sparrow: adaptive strategy for floaters. Am Nat 112:571-582

Stamps JA (1995) Motor learning and home range value. Am Nat 146:41-58

Stamps JA (2001) Habitat selection by dispersers: integrating proximate and ultimate approaches. In: Clobert J, Danchin E, Dhondt AA, Nichols JD (eds) Dispersal. Oxford University Press, New York, pp 230-242

Stamps JA, Krishnan VV (1999) A learning-based model of territory establishment. Q Rev Biol 74:291-318

Stamps JA, Krishnan VV, Reid ML (2005) Search costs and habitat selection by dispersers. Ecology $86: 510-518$
Stutchbury BJ (1991) Floater behaviour and territory acquisition in male purple martins. Anim Behav 42:435-443

Thield A, Hoffmeister TS (2004) Knowing your habitat: linking patch encounter rate and patch exploitation in parasitoids. Behav Ecol 15:419-425

Turchin P (1996) Fractal analyses of animal movement-a critique. Ecology 77:2086-2090

Vos M, Hemerik L, Vet LEM (1998) Patch exploitation by parasitoids Cotesia rebecula and Cotesia glomerata in multi-patch environments with different host distributions. J Anim Ecol 48:353-371

Vuilleumier S, Perrin N (2006) Effects of cognitive abilities on metapopulation connectivity. Oikos 113:139-147

Waser RF, Creel SR, Lucas JR (1994) Death and disappearance, estimating mortality risk associated with philopatry and dispersal. Behav Ecol 5:135-141

Wiens JA, Crist TO, With KA, Milne BT (1995) Fractal patterns of insect movement in microlandscape mosaics. Ecology 76:663-666

With KA (1994) Ontogenetic shifts in how grasshoppers interact with landscape structure: an analysis of movement patterns. Funct Ecol 8:477-485

Worton BJ (1989) Kernel methods for estimating the utilization distribution in home-range studies. Ecology 70:164-168

Zack S, Stutchbury BJ (1992) Delayed breeding in avian social systems: the role of territory quality and "floater" tactics. Behaviour 123:194-219

Zollner PA, Lima SL (1999) Search strategies for landscape-level interpatch movements. Ecology 80:1019-1030 